Sādhanā, Vol. 14, Part 3, December 1989, pp. 187-212. Printed in India.

\title{
Five-kilowatt wood gasifier technology: Evolution and field experience
}

\author{
S DASAPPA, U SHRINIVASA*, B N BALIGA and H S MUKUNDA** \\ Centre for the Application of Science \& Technology to Rural Areas \\ (ASTRA), *Department of Mechanical Engineering, and \\ **Department of Aerospace Engineering, Indian Institute of Science, \\ Bangalore 560012, India
}

MS received 28 January 1990; revised 23 March 1990

\begin{abstract}
Various elements of an efficient and reliable $5 \mathrm{~kW}$ wood gasifier system developed over the last ten years are described. The good performance obtained from the system is related to the careful design of its components and sub-systems. Results from extensive testing of gasifier prototypes at two national centres are discussed along with the experience gained in the field from their use at more than one hundred and fifty locations spread over five states in the country. Issues related to acceptance of the technology are also included. Improvements in design to extend the life, to reduce the cost, and to reduce the number of components are also discussed. A few variants of the design to meet the specific requirements of water pumping, power generation and to exploit specific site characteristics are presented.
\end{abstract}

Keywords. Five-kilowatt wood gasifier; throatless design; testing; field trials; performance; gas cooling; gas cleaning; biomass gasification.

\section{Introduction}

Based on the Swedish experience with gasifiers during the Second World War as reported in the SERI translation (SERI 1979) and also from our own experience gained from designing, testing and evaluating four prototypes in about five years, a successful design of a choke plate gasifier was evolved. Shrinivasa \& Mukunda (1984) give details of this design and also of a few other classical designs evolved over a period of about 200 years. More details of classical designs are available in SERI (1979), Kaupp \& Goss (1984) and Reed (1981). The prototypes went through about four hundred hours of testing and the design was slated for batch production. At this juncture a throatless gasifier, discussed in Reed et al (1984) but different from the one proposed by them in a few aspects, was also being tested in the laboratory. The performance of the latter turned out to be so promising that plans for batch production of the earlier design were abandoned and the development of the throatless gasifier was taken up.

There have been only two other attempts known to us, other than that of Reed 
et al (1984), to build prototypes of throatless wood gasifiers (private communication, H La Fontaine 1985, and RAPA 1988a) even though such designs are commonly used for pyrolysing rice husk (RAPA 1986, 1988b). However there is no indication of these attempts resulting in mature designs for gasifying wood. In India we know of only one work (RAPA 1988a) in which the development of a throatless gasifier was attempted basically for sugar cane tops. Our designs differ from the conventional choke-plate designs mainly in two aspects. The throatless gasifier has a relatively simpler geometry for its reactor and both the fuel and the air are introduced from the top of the reactor. In the present attempt an additional air nozzle is provided at the combustion zone making the design different from both the types mentioned above. The modification substantially improves the performance and the reliability of the reactor. A few prototypes were built and tested for various durations. The following sections report on their development, testing and dissemination in the past five years.

\section{Principles of design}

The main problem of biomass gasifier design is in effecting combustion-reduction operations in such a way that there is very little tar and dust in the gas generated (a tutorial sketch of the gasifier, with the processes taking place marked on it, is given in figure 1). Further, at the reduction zone exit, in order to prevent caking of the ash, the temperature should not exceed ash-fusion temperature. To avoid tar, the entire stream of combusting fuel-oxidant mixture should be made to pass through a sufficiently hot zone at temperatures exceeding $1200 \mathrm{~K}$ (see SERI 1979).

In order to achieve the above, the classical design uses a throat or a constriction in the flow passage which is much smaller than the chamber cross-section. The entire combustion is expected to be mostly restricted to a region around the throat where also the air is introduced. By reducing the throat and the diameter of the air entry region, the combustion volume may be made smaller thus causing the air to fuel ratio to tend towards the stoichiometric ratio and the temperature of the combustion zone to rise. The higher temperature helps in the burning of the long chain molecules, including tar, produced by the pyrolysis of the charge. However, because the throat experiences high temperatures and reducing atmosphere, its life is less than that of other parts. In our earlier design, the throat used to be a replaceable cast component whose improper positioning would introduce leakage paths and the gas thut came out would invariably have traces of tar. On the other hand, if the throat were fixed by welding or with bolts, the frequent replacements required because of its relatively short life would be difficult to carry out in the field. We grappled with this problem for a considerable length of time with no success in sight. It was thought at that time

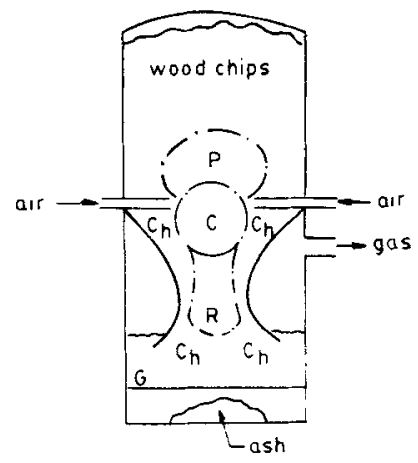

Figure 1. A tutorial sketch of a gasifier reactor (Shrinivasa \& Mukunda 1984); Ch: char, P: pyrolysis, C: combustion, R: reduction, G: grate. 


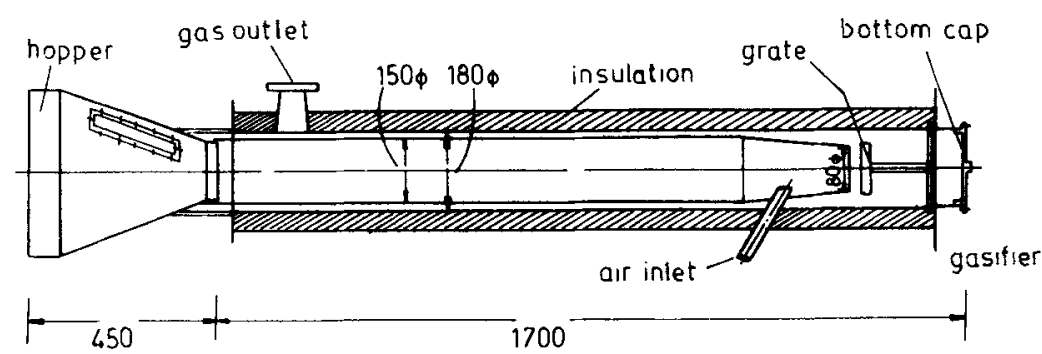

Figure 2. Throatless gasifier reactor (dimensions are in millimetres). When in use, the unit is mounted vertically with the hopper at the top.

that the reduction zone and the throat assembly could be supported by an annular plate and the junction could be sealed with fireclay. Even in ihe laboratory this had only limited success. Under the circumstances, the throatless design is of great advantage. Its evolution as described here occurred independently to overcome the problems in the field associated with classical designs.

The combustion chamber in our version of the throatless gasifier is sized a little larger than the reactor diameter at the air inlet. The increase is to keep the wall slightly away from the combustion zone. The combustion and the reduction zones are not separated, but are contiguous and extend right upto the grate. The distance from the air inlet (figure 2) to the grate is taken from the design curves given in SERI (1979). The chamber wall is kept slightly converging from the air entry zone up to the end of the reduction zone to keep the velocity in the grate zone high enough to facilitate the blowing away of any ash which may collect or agglomerate there. However, it is likely that a cylindrical configuration may be equally satisfactory. In the $5 \mathrm{~kW}$ version the chamber diameter is $150 \mathrm{~mm}$ and the cone is reduced to a diameter of $80 \mathrm{~mm}$ (see figure 2 for details). The other aspects of the gasifier, like the cooling and the cleaning systems, are similar to those in Dasappa et al (1985).

Another important feature of the present design is that the hot gases leaving the grate move upward in the annular space between the inner and the outer cylinders (see figure 2). The entire height of the reactor which has an $L / D$ (length to diameter ratio) larger than 8 is heated by hot gases. The outer cylinder is well-insulated on the outside by a layer of $75 \mathrm{~mm}$ thick aluminosilicate insulation material. In the field version, to reduce cost, two la:ers amounting to $50 \mathrm{~mm}$ thickness of aluminosilicate wool and one $25 \mathrm{~mm}$ layer of glass wool are used upto $50 \%$ of the height from the bottom; for the remaining height a $75 \mathrm{~mm}$ thick layer of only glass wool is used. Hence most of the heat recovered from the hot gases is transferred through the wall to the wood pieces loaded into the reactor thereby reducing the extent of cooling required to use the gases for engine operation. This aspect of the design is a new addition to that propc sed by Reed et al (1984). Because of the facility for heating wood chips and the resulting stratification of the pyrolysis and combustion processes along the length of the gasifier, its start-up time is short and the design can utilise relatively wet wood chips with moisture contents upto $25 \%$.

In classical designs, since a single charge of wood chips is meant for several hours of operation the fuel container is generally of larger diameter than the combustion zone. In the current design, the fuel container is limited to the diameter at the air entry zone which is $150 \mathrm{~mm}$ as already indicated. Therefore, even with an $L / D$ of 8 the reactor can hold only about $9 \mathrm{~kg}$ of wood pieces which is enough for about two and a half hours of operation of a $3.7 \mathrm{~kW}$ diesel engine at $2.5 \mathrm{~kW}$ output. For extended durations of operation, since the top is kept open, a hopper loaded with wood chips. is placed on it. This would suffice for about four hours without requiring any further 
loading, a feature which is satisfactory for most purposes. For longer runs, the wood chips in the hopper will have to be periodically replenished.

The open top concept, with a relatively smaller reactor diameter has several advantages. Along any diameter of the gasifier section there could be approximately four to five wood pieces. Since the average bulk density is about $350-400 \mathrm{~kg} / \mathrm{m}^{3}$ (when the single piece density is $650-700 \mathrm{~kg} / \mathrm{m}^{3}$ ) there is enough void space for the heat transferred by radiation from the walls to penetrate the entire cross-section. Thus the entire volume gets heated, and the local temperature inside the reactor varies from about $1100 \mathrm{~K}$ at the bottom zone to about $425 \mathrm{~K}$ at the top. This helps in driving out from the top the moisture present in the wood pieces and drying them better as they move down towards the air nozzle. The increasingly high temperatures towards the air nozzle help in the pyrolysis of wood pieces and also in their smooth downward movement without sticking to each other or to the walls through the combustion zone.

The air for combustion inside the reactor comes from two sources, (i) an air inlet nozzle of $19 \mathrm{~mm}$ inner diameter, and (ii) the open top through the bed of fuel chips. About $60-65 \%$ of the air comes from the air nozzle and the rest from the top. Reed et al (1984) did not explore this alternative of having an air inlet nozzle in the lower zone. Since all the air was drawn from the top through the bed of wood chips, the average combustion temperatures were lower $(1300 \mathrm{~K}$ or lower) and this could have resulted in poor quality gas at lower rates of gas generation.

Induction of air from the top causes what is termed as stratification of the fuel charged. The volatiles are released at some stage in the downward path of wood chips. Mixing with air from the top causes initiation of exothermic reactions and the rise in temperature becomes steep in this zone. The transfer of heat to the upper zone causes an earlier initiation of the release of volatiles. This would mean that an isotherm, say at $700 \mathrm{~K}$, slowly creeps upwards and the gasifier never attains a steady state during the few hours of its operation in terms of the thermal profile both in the reactor and in the annular space, as long as air is drawn from the top. If the supply of air from the top is cut off, the temperatures inside the gasifier and the annular space would attain a steady state about an hour after the cut-off. It is important to note that the gas quality is not affected by the non-attainment of a thermally steady state in the gasifier. It is possible that there is some shift in gas composition, but it does not seem to have any significant effect on the calorific value of the gas. The calorific value remains steady and within about $20 \%$ of the average throughout the

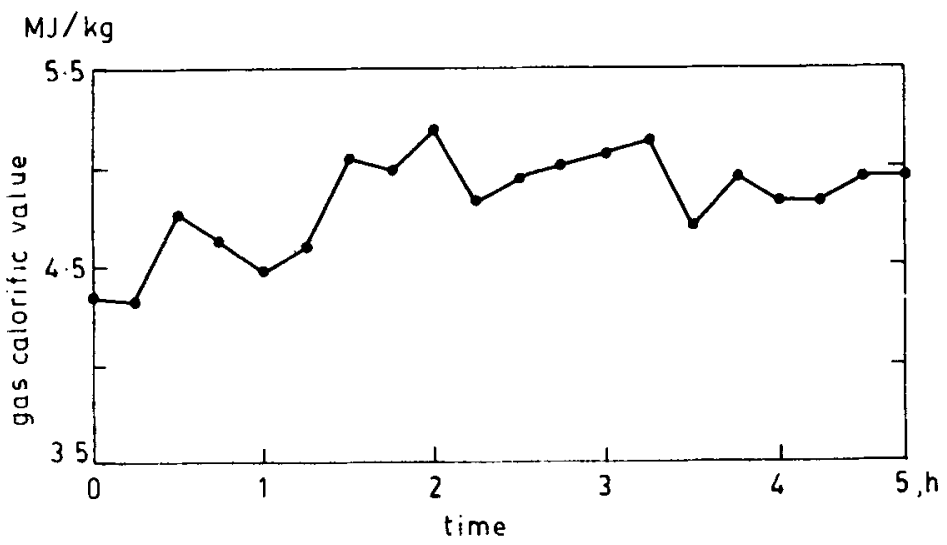

Figure 3. Variation of calorific value with time from the ignition of the gasifier (gas flow rate about $3 \mathrm{~g} / \mathrm{s}$ ). 
period (see figure 3). The significant advantage of the features described above is that they help even the relatively wet wood chips (upto $25 \%$ moisture content) to get dried and charred before reaching the second air entry region at the air nozzle.

Another benefit from passing the hot gases through the annular space is with regard to how the material movement is facilitated inside the reactor. As mentioned earlier, an isotherm of $700 \mathrm{~K}$ is established along the length of the gasifier. Hence there is no possibility of any condensibles (tar) sticking to the wall and causing bridging, thus assuring reasonably good material movement.

\subsection{The cooling system}

The temperature of the gas at the exit of the gasifier goes up from about $330 \mathrm{~K}$ to $450 \mathrm{~K}$ in about an hour to an hour and a half depending on the gas flow rate. It was debated whether one should use a cooling system based on spraying water into the hot gases or a dry system where the cooling is effected by losses from the wall of a circular duct in which the gas is made to flow. The advantage with a dry cooling system is that there is no requirement of water, something which may be important in electrical applications. The disadvantage is that the cooling system size and cost will be larger. In the early versions of the system, only a dry cooling system had been incorporated. Since many applications involving water pumping turned up later, a version with a water cooling system was introduced. The choice of one or the other of the cooling systems could be based on site requirements.

The early version of the dry cooling system consisted of a stainless steel baffled rectangular chamber $35 \mathrm{~mm}$ wide, $1000 \mathrm{~mm}$ high and $1000 \mathrm{~mm}$ long, separated into five sections (figure 4). The chamber with the bottom open was placed in a container of water which also provided the water seal. The gas flows through the various sections and loses heat through the walls. This cooling system worked well at flow rates upto $3.5 \mathrm{~g} / \mathrm{s}$, but was not efficient for higher flow rates i.e., the gas temperature went up beyond $313 \mathrm{~K}$, the acceptable limit for use in engines.

Subsequently, we thought of replacing the complex construction described above

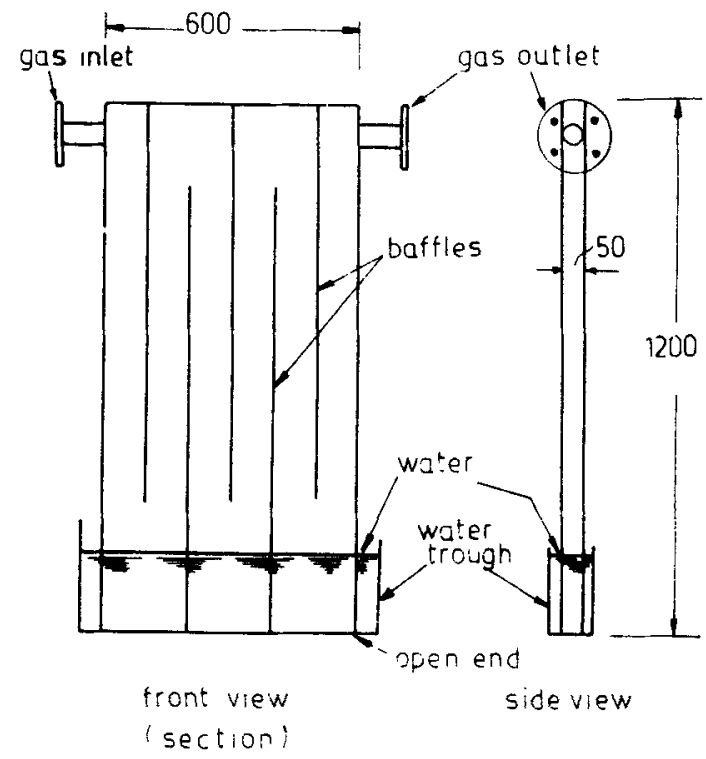

Figure 4. Early version of the dry cooling system (dimensions in $\mathrm{mm}$ ) (Dasappa et al 1985). 


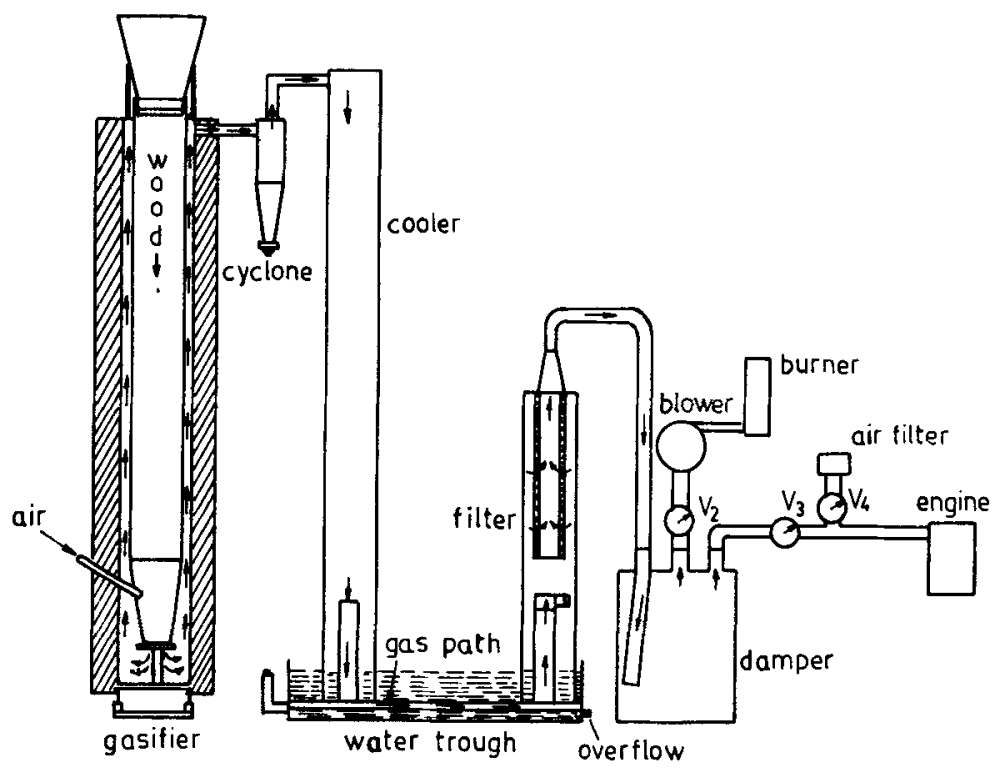

Figure 5. Gasifier and the cooling-cleaning system.

by a cylindrical tube. Figure 5 shows the details of this construction. The gas exits from the annular space through a cyclone and tangentially enters the top of the aluminium cooler tube. As before, the cooling is mostly due to the losses from the tube wall. Towards the bottom, the gas enters a central duct, goes to the bottom section and impinges on the water for cleaning the gas and for cooling it further. The gas skims over the water and exits into a second tube tangentially, losing further heat to it. The gas then flows through a fabric and coir filter cartridge and into a duct which carries the gas to the engine through a damper. This passive cooling system performs satisfactorily up to a gas generation rate of about $3 \mathrm{~g} / \mathrm{s}$ suitable for an engine-generator system of $3.5 \mathrm{~kW}$ electrical output. As many as a hundred of the gasifier engine systems deployed so far have such coolers.

\subsection{The cleaning system}

The gas delivered by the gasifier has carbon dust, some tar and water vapour. It is important that the first two are brought to very low levels and the water vapour brought to equilibrium levels at the ambient temperature of $313 \mathrm{~K}$ or lower.

The first element of the cleaning system is the cyclone. The cyclone collects fine carbon dust (above 10 micrometres in size) at efficiencies upto $85 \%$ at nominal flow rates of $3.5 \mathrm{~g} / \mathrm{s}$. Since the gas velocities are high in the cyclone (about $10 \mathrm{~m} / \mathrm{s}$ ), it also acts as a good cooling device and reduces the temperature of the gas by $100-150 \mathrm{~K}$ depending on the inlet temperature.

The rest of the cleaning system captures varying amounts of dust and tar, but these elements are incapable of preventing fine dust (of 3-10 micrometres) from reaching the engine. Also some traces of the undesirable tar inevitably escape. The size of the dust particles just indicated is small enough to be ingested into the engine without deposition anywhere nor could it be retained by the systems described earlier. A study of filters described in Strauss (1975, pp. 248-314) showed that the gas has to be passed through a fine fabric filter of reasonable thickness at velocities of no more than 
$3-5 \mathrm{~cm} / \mathrm{s}$. Under these circumstances the gas going through a tortuous path leaves behind the fine dust, and possibly also some tar, to a significant extent. The low velocity implies the use of a large area. The second cleaning element which is the filter consists of a thick mat of coconut coir rolled up into a hollow cylinder of total area $0.3 \mathrm{~m}^{2}$ and a wall thickness of $30 \mathrm{~mm}$. The coir is also known to have an affinity for removing moisture.

\subsection{Performance of the gasifier}

A schematic sketch of the entire gasifier-burner-engine system is shown in figure 5 . A typical start-up sequence is as follows: The electric blower (a hand blower in the field) is first turned on. This begins to draw the air through the system, partly from the nozzle and partly from the top. Introduction of a burning wick near the air inlet causes ignition of the charcoal inside the reactor and within two minutes we get a combustible gas at the burner. The gas is either led tangentially into a burner to check when it becomes ignitable or is allowed to be inducted into the engine via another circuit bypassing the blower.

Typical measurements include -

- flow rates of the air and the gas (using calibrated venturimeters),

- average consumption rate of the wood chips,

- temperatures at the end of the reduction zone, at the inlet and exit of the cyclone, and at the end of the cooling circuit (using chromel - alumel thermo-couples),

- power delivered by the engine-generator set,

- flow rate of water and the head developed by the pump if an engine pump set is used,

- flow rate of diesel using a burette and a timing device,

- gas composition in selected cases using an Orsat apparatus and in a few instances using a gas chromatograph,

- calorific value using the Junkers gas calorimeter.

Particulates and tar are measured by a simple technique which involves the collection of these on a thick cotton wad of about $0.1 \mathrm{~m}$ diameter placed in the circuit at the end of the cooling-cleaning system for a specific period of time (typically 30 to $45 \mathrm{~min}$ ). The cotton is weighed before and after the test. The difference is taken to be the weight of both tar and particulates put together. The material depositied on cotton is later dissolved in ethyl alcohol and filtered. What is left behind on the filter paper constitutes particulate matter and that passing through the filter paper is tar. This presumes that all tarry matter is soluble in alcohol (almost all the constituents, about two hundred of them, listed under tar in Kaupp \& Goss 1984, are soluble in alcohol). A further assurance that no undesirable material escapes the test filter is obtained in specific tests by providing a second filter downstream of the first one. Negligible changes in appearance or weight have been noticed in the second filter and therefore it is taken that almost all the material has been captured by the first filter itself.

While most of these measurements were complete by the middle of 1987 , the dissemination of these gasifiers called for a rigorous testing by testing centres duly appointed by the Government. Tests on these gasifiers have been conducted at the Indian Institute of Technology (IIT), Bombay, by Parikh et al (1988) and at the Madurai Kamaraj University by Haridasan et al (1989). The former tests were far more detailed 
than the latter ones which were limited to overall parameters. Results obtained by Parikh and coworkers are available under two different types of tests. One of them is reported in Parikh et al (1988). The other refers to tests on the system as a part of the test and qualification programme of the Government of India (Bhama et al 1988). Results from these two tests refer to biomass of different moisture contents $(12-15 \%$ in the first case and $18-23 \%$ in the second). The results are broadly similar but significant differences exist with respect to (a) calorific value, and (b) tar and particulate content of the gas after cleaning. They will be discussed subsequently. There is complete consistency in the results obtained by us at the laboratory and those obtained at the two external centres on most of the measurements. These include, the extent of diesel replacement and the operational reliability of the system. Certain aspects concerning the life of the system like the early cracking of the air inlet nozzle region was also noticed at all these places and at certain other field stations (Rao 1989). The major point of difference concerns the extent of tar and particulate matter. The values reported by Parikh et al (1988) and Bhama et al (1988) seem to be in excess of the values measured by us. The latter values seem to be marginally important as far as the acceptability to engine operation is considered. These aspects of the measurement and the subsequent changes made on the system to obtain better quality gas are described below, where the performance aspects reported belong to those made by us. Only in those cases where there were differences between our measurements and those of other test centres, both the measurements are presented and discussed.

\subsection{Gasifier performance in blower mode}

2.4a Gas composition and calorific value: Runs with the blower at prespecified gas flow rates were made to assess the quality of the gas, and the efficiency of the cleaning circuit. The typical gas composition obtained over several runs is shown in table 1. The variation of gas calorific value as a function of the time of operation is shown in figure 3. The calorific value seems to increase from about 4.2 to $5.3 \mathrm{MJ} / \mathrm{kg}$ in the first one hour and seems to remain steady around this value when the gasifier is charged afresh. This slow increase in the calorific value may be correlated to the expected reduction to some extent in bed porosity with time (and thereby reduced gas tunnelling and improved gas-solid contact) when the gasifier is charged afresh. It must be noted that air-dried wood chips with an average moisture content of about $10-12 \%$ were used. At higher moisture contents one should expect lower calorific values but not necessarily equivalent to what could be calculated taking into account the additional moisture, because the chemical equilibrium of the gases generated in the reduction zone may be altered. The values reported by Parikh et al (1988) and Bhama et al (1988) are shown in table 2. A careful study of the comparison of the

Table 1. Composition of gas obtained in blower-mode operation.

\begin{tabular}{llllll}
\hline \multirow{2}{*}{$\begin{array}{l}\text { Gas flow rate } \\
(\mathrm{g} / \mathrm{s})\end{array}$} & \multicolumn{5}{c}{ Average gas composition (\%) } \\
\cline { 2 - 6 } & $\mathrm{N}_{2}$ & $\mathrm{CO}$ & $\mathrm{CO}_{2}$ & $\mathrm{H}_{2}$ & $\mathrm{CH}_{4}$ \\
\hline 1.5 & 44 & 21 & 13 & 20 & 2 \\
2.5 & 47 & 20.5 & 11.5 & $18 \cdot 5$ & $2 \cdot 2$ \\
4.0 & 46 & 19.5 & 12.5 & 20 & $2 \cdot 0$ \\
\hline
\end{tabular}


Table 2. Gas calorific values measured at ilt, Bombay.

\begin{tabular}{lccc}
\hline Source & $\begin{array}{c}\text { Calorific value } \\
(\mathrm{MJ} / \mathbf{k g})\end{array}$ & $\begin{array}{c}\text { Moisture content } \\
\text { of wood }(\%)\end{array}$ & Operation \\
\hline $\begin{array}{c}\text { Parikh et al } \\
(1988)\end{array}$ & $5 \cdot 2-5.8$ & $13.5 \pm 1.5$ & Engine mode \\
$\begin{array}{c}\text { Bhama } \text { et al } \\
(1988)\end{array}$ & $5 \cdot 4-7.1$ & $19.5 \pm 3$ & Engine mode \\
\hline
\end{tabular}

calorific value and the composition showed that these are consistent within a few percent in most cases. The magnitudes of the calorific value seem consistent with the measurements in our laboratory except in the second test of Bhama et al (1988) where the calorific value goes to a high $7 \cdot 1 \mathrm{MJ} / \mathrm{kg}$. In some of these cases the moisture level is as high as $23 \%$. It does not appear that these high values of calorific value can be justified except when the methane content is unusually large. This can happen when the gasifier operation leads to the pyrolysis gases not being processed in the system as normally expected. Such an operation can also account for the larger amounts of tar but lesser particulates.

2.4b Starting sequence: In the recommendation made by us for a proper operational procedure in the dual fuel mode, it has been suggested that the engine can be switched on to dual fuel operation within a few minutes after the gas ignites in the burner. The flaring is claimed to be guaranteed within two minutes of starting if all initial conditions of the set-up are normal. While the test of Parikh et al (1988) and Haridasan et al (1989) confirm the above claim, it has been suggested by Bhama et al (1988) that the switch-over to dual fuel mode should be attempted 30-60 min after the gasifier has been started. This is based on their measurements in which the gas-outlet temperature (before the cyclone) had not attained steady state, but continued to increase for three to four hours after start. While this result is accepted as correct, the interpretation appears illogical and we suggest that the original recommendation be adhered to, without any concern regarding the performance of the system. The outlet gas temperature versus time from our measurements and from those of Bhama et al (1988) are shown in figure 6a. While Parikh et al (1988) report measurements for
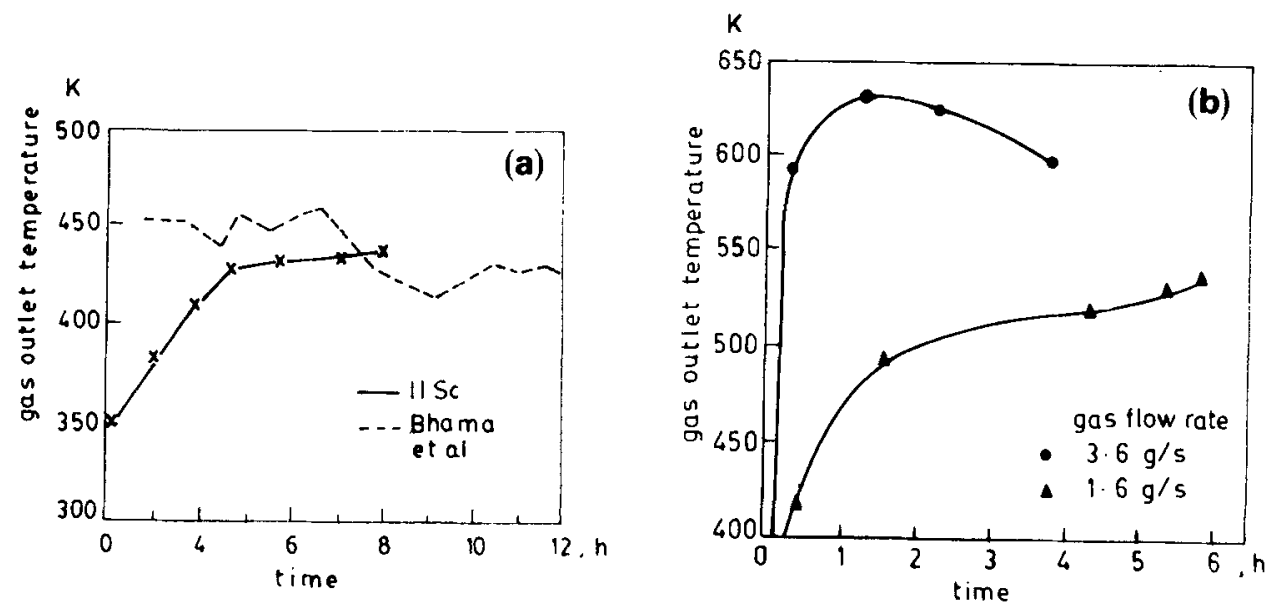

Figure 6. (a) Variation of gas temperature at gasifier outlet with time from ignition (IISc data at a gas flow rate of $2.5 \mathrm{~g} / \mathrm{s}$ ). (b) Variation of gas temperature at gasifier outlet with time from ignition (Parikh et al 1988). 
a number of flow rates, the results of only two flow rates are shown in figure 6b. (The measurements shown in these two figures are approximately consistent if we take into account that there is a problem in measuring the temperature of a hot gas in a duct with cold walls. No extra precautions appear to have been taken and therefore only the trend that the gas temperature takes time to stabilise needs to be considered.)

Measurements of the reduction zone temperature have shown that the end of the reduction zone reaches $900 \mathrm{~K}$ in the first three minutes at $2 \mathrm{~g} / \mathrm{s}$ and in two minutes at $3 \mathrm{~g} / \mathrm{s}$ and so on, the time interval becoming shorter as flow rate increases. Thus the response of the gasifier in producing good quality combustible gas depends on the flow rate.

The exit gas temperature is low initially because the hot gases transfer heat to the cold outer wall and to the relatively cooler zones of the inner wall, which in turn lose heat to the wood chips.

As time progresses, the rate of heat transfer to the walls becomes less because the wall gets heated up with time and less heat is drained from the gases. This is the reason for the slow rise in temperature of the gases at the exit. It does not have anything to do with the quality of the gas generated. In addition to the above, in any given fresh run the gas generated in the first fifteen minutes is due to the gasification of the charcoal either from the previous run or from the fresh charge. As such one should expect very little tar. Handling of the particulates is nothing special to the starting condition. The quality of the gas being allowed to be ingested by the engine should not only be satisfactory, but should be quite good even within the first ten minutes. Curiously, the results of Bhama et al (1988) regarding tar and particulate matter versus time as shown in figure 7 confirm the fact that early periods of operation have perhaps less tar compared to later times. (Steady increase of particulates in the gas after six hours of operation, as shown in figure 7 could be due to the limited ash-holding capacity of the particular prototype.)

An additional reason why there is no steady state of the exit gas temperature is that the operation of the gasifier is partly stratified as explained earlier. This implies that the pyrolysis zone is continuously moving up inside the reactor at a rate dependent on the air-flow rate from the top and the gas generation rate. These do not affect the quality of the gas as far as ingestion into the engine is concerned.

What is important for smooth engine operation and high diesel replacement is a reasonably clean gas with sufficiently energy (calories) in the mass of the gas inducted into the cylinder in each cycle. The measurements shown in figures 3 and 7 and the

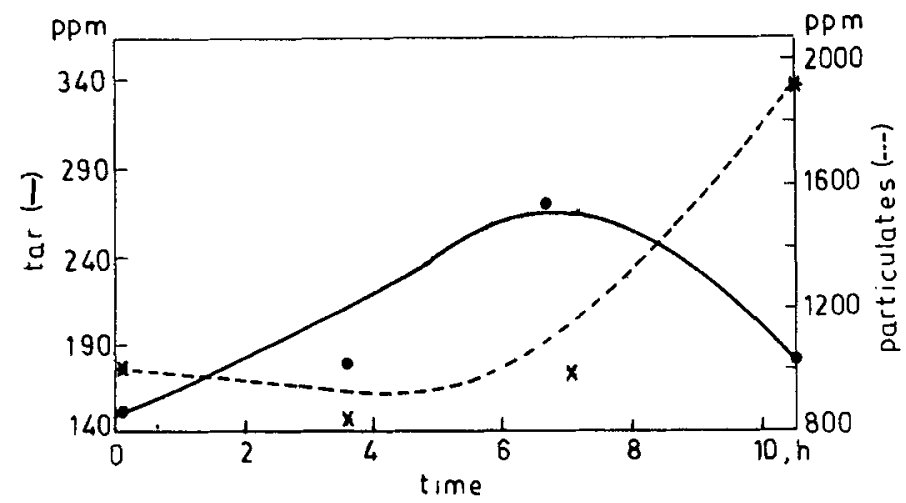

Figure 7. Variation of tar and particulate matter with time from ignition (Bhama et al 1988). 
Table 3. Tar and particulate levels in the gas after cooling and cleaning.

\begin{tabular}{lcc}
\hline Flow rate $(\mathrm{g} / \mathrm{s})$ & Tar (ppm) & Particulates (ppm) \\
\hline 3 & $50-100$ & $100-150$ \\
2 & $50-120$ & $80-100$ \\
\hline
\end{tabular}

fact that the gas is cooled to almost the ambient temperature assure that it is good enough for use in the engine a few minutes after igniting the gasifier.

2.4c Tar and particulates: Measured values of these two quantities by a procedure indicated earlier are presented in table 3.

Measurements by Parikh et al (1988) and Bhama et al (1988) seem very different. The tar amounts to $40-120 \mathrm{ppm}$ and the particulates to $50-300 \mathrm{ppm}$ in the first study, and to $150-180 \mathrm{ppm}$ and $460-1000 \mathrm{ppm}$ in the second study, respectively. It is not clear which of these two sets of data is appropriate. The first set of data is closer to our measurements. SERI (1979) reports the following:

"There are many divergent opinions as to the acceptable content of solid dust particles in the gas after cleaning. French regulations allow $5 \mathrm{mg} / \mathrm{m}^{3}$ for charcoal gas operation and $20 \mathrm{mg} / \mathrm{m}^{3}$ for wood gas operation; other specifications are: $50 \mathrm{mg} / \mathrm{m}^{3}$ for both charcoal and wood gas (Finkbeiner 1937); $20 \mathrm{mg} / \mathrm{m}^{3}$ (Lutz \& Kuhl 1942), among others. In practice the dust content is much higher, as indicated by many tests, ranging from $50-200 \mathrm{mg} / \mathrm{m}^{3}$, with the lowest values found when cloth filters are used and the highest for baffle-plate cleaners, which at the same time act as coolers.

Provided that the air cleaner for the secondary air is functioning properly, an average dust content in the mixer pipe of 10 to $20 \mathrm{mg} / \mathrm{m}^{3}$ is quite satisfactory. When a high content of silicon and iron compounds are involved, the above-mentioned maximum figure should probably be divided by half...

In laboratory tests by the Swedish Steam Heat Institute in October 1944 on a Volvo passenger car equipped with an Imbert generator with a V-hearth and using hard-wood fuel of $13.5 \%$ moisture content, the following results were obtained:

Test 1 at $70 \mathrm{~km} / \mathrm{h}$ : Tar content in gas leaving the gas outlet-approximately $0 \cdot 34 \mathrm{~g} / \mathrm{m}^{3}$.

Test 2 at $30 \mathrm{~km} / \mathrm{h}$ : Tar content in gas leaving the gas outlet-approximately $0.64 \mathrm{~g} / \mathrm{m}^{3}$.

These magnitudes of tar and particulates seem higher than are acceptable to the engine."

Certainly the tar and particulate levels shown in table 3 appear to be only marginally acceptable from the above experience. Therefore an effort has been made to reduce these levels further as is described in $\$ 2.16$.

\subsection{Duration of continuous operation}

The gasifier has a bottom cap which has a groove in which an asbestos O-ring is set to fit tightly against the metal of the shell. This provides a seal against leakage into the system. Any small leakage of air into the system is disastrous because the hot 
combustible gas just out of the reduction zone burns with the leaking air to produce very high combustion temperatures $(1800 \mathrm{~K})$ and causes melting of the bottom part of the reactor shell.

During normal operation the space between the bottom part of the grate and the bottom cap is available for the accumulation of the ash. At a gas generation level of around $3 \mathrm{~g} / \mathrm{s}$ corresponding to an operating power level equal to $3.7 \mathrm{~kW}$ electrical, the space provided is sufficient to collect ash for uninterrupted operation of $20 \mathrm{~h}$. In some field situations problems have been faced when the operating period has exceeded $15 \mathrm{~h}$. The design was originally meant for $4-5 \mathrm{~h}$ of operation per day so that system cleaning and restarting could be done once in four to five days.

\subsection{Moisture content}

The moisture content of the wood chips is an important parameter in ensuring consistent gasifier performance. The experience on gasifiers of classical design was that the performance was poor if the moisture content of the wood chips was large $(>20 \%)$. Wood chips would be found reaching the air nozzle region more frequently and on occasions even the reduction zone. This would mean the generation of volatiles with large contents of hydrocarbons getting out unburnt in the combustionreduction zone. The exit gases would have a much larger fraction of tarry compounds. On some days (when the wood chips were dry), the gasifier would perform very well and on others (perhaps when the wood chips were quite wet) it would perform poorly.

In the current design, the partial admission of air from the top helps in the removal of moisture, the release of volatiles, and their reaction with air in a zone much above the air nozzle. Thus it is the char which appears at the air nozzle zone because of which the gasifier functions normally.

Due to the above advantageous features, wood chips with moisture contents as high as $25 \%$ have not posed problems. Of course, one cannot start with wet wood chips at this level of moisture. However an hour from the start when the inner wall has become hot ( $450 \mathrm{~K}$ and above), the loading of wet wood chips with moisture levels up to $25 \%$ still produces satisfactory performance. Wood consumption rate per kilowatt goes up. These are shown in table 4. In the table the values of the quantities of wood in kilograms replacing a litre of diesel are also given.

Bhama et al (1988) conclude that $\mathrm{kg} /$ litre of diesel replaced is higher for the present gasifier compared to the "standard" value of $4.0 \mathrm{~kg} / \mathrm{litre}$. It is not clear whether it has been recognised that this value is dependent on the amount of moisture in wood. The results from table 4 show that the expectation of higher wood consumption per litre of diesel replaced at higher moisture content is entirely reasonable.

Table 4. Variation of wood consumption rate per $\mathrm{kW}$ (of electricity generated) with moisture content (Haridasan et al 1989 and Bhama et al 1988).

\begin{tabular}{lccc}
\hline$\%$ Moisture & $\begin{array}{c}\text { Percentage diesel } \\
\text { replacement }\end{array}$ & $(\mathrm{kg} / \mathrm{h}) / \mathrm{kW}$ & $\begin{array}{c}\mathrm{kg} / \text { litre of diesel } \\
\text { replaced }\end{array}$ \\
\hline $10-12$ & 82 & $1.05 \pm 0.02$ & 3.7 \\
$18-22$ & 78 & $1.10 \pm 0.02$ & 4.4 \\
\hline
\end{tabular}




\subsection{Use of nonwoody biomass in the gasifier}

We have investigated the use of non-woody biomass like corn-cobs, arecanut husk and coconut shells in the gasifier because there are regions in the country where they are available in large amounts. Corn-cobs were simply broken into two or three pieces and the entire mass was loaded into the reactor after start-up on charcoal. Arecanut shells were loaded without any pretreatment. Table 5 provides data on their average and bulk densities. The densities are significantly lower than that of wood in the first two cases. Experience suggested that both corn-cobs and arecanut husks could be gasified and in fact engines were run on the gas produced, but material movement posed problems. Shaking the gasifier was necessary far more frequently for corn-cobs than for wood (once in every $30 \mathrm{~min}$ in comparison to once in an hour and a half for wood). Arecanut husks posed more serious problems. Shaking was necessary, but not adequate. It was necessary to agitate the top, but not harshly, at a frequency of once in thirty minutes. From this experience, it was concluded that corn-cobs could be used with some effort, but arecanut husk would, by itself, not be a satisfactory fuel for the gasifier. It is not difficult to feed a mix of wood chips and arecanut husks in equal proportions by weight and run the system satisfactorily. Whether such a possibility is realistic in field situations is not easy to say. It was also recognised that the availability of corn-cobs is seasonal and of arecanut husks is partly so. One can therefore conceive of these alternatives only in conjunction with the availability of wood if the gasifier system is to be operated throughout the year.

Coconut shells, broken to a size comparable to that recommended for wood chips, were used in the gasifier. It was found that the calorific value of the gas was higher than that obtained with wood and varied between 6 and about $7.5 \mathrm{MJ} / \mathrm{kg}$. The higher calorific value can be attributed to the low moisture content (about $7 \%$ ) of the coconut shells. There seemed to be no problems of material movement when adhering to the recommended size of chips. Engine runs were carried out and an average diesel replacement of about $80 \%$ has been obtained over a range of loads up to about $80 \%$ of the rated load in the $3.7 \mathrm{~kW}$ system.

\subsection{Performance with engine}

The normal scheme of operation with the engine is shown in figure 5. First, the gas line is closed and the air line is kept open. The engine is started on diesel. After about five minutes when the engine has warmed up, and after the gasifier has been started, the gas valve to the engine is opened. This causes the diesel governor to reduce the diesel to maintain the set RPM. The system is then loaded to the desired level. Further optimisation of diesel flow can be achieved by carefully reducing the air-flow into

Table 5. Particle and bulk densities of a few samples of nonwoody biomass.

\begin{tabular}{lcc}
\hline Materials & $\begin{array}{c}\text { Average density } \\
\text { per piece }\left(\mathrm{kg} / \mathrm{m}^{3}\right)\end{array}$ & $\begin{array}{c}\text { Bulk density } \\
\left(\mathrm{kg} / \mathrm{m}^{3}\right)\end{array}$ \\
\hline Corn-cobs & 250 & 150 \\
Arecanut shells & 150 & 100 \\
Coconut shells & 900 & 500 \\
\hline
\end{tabular}




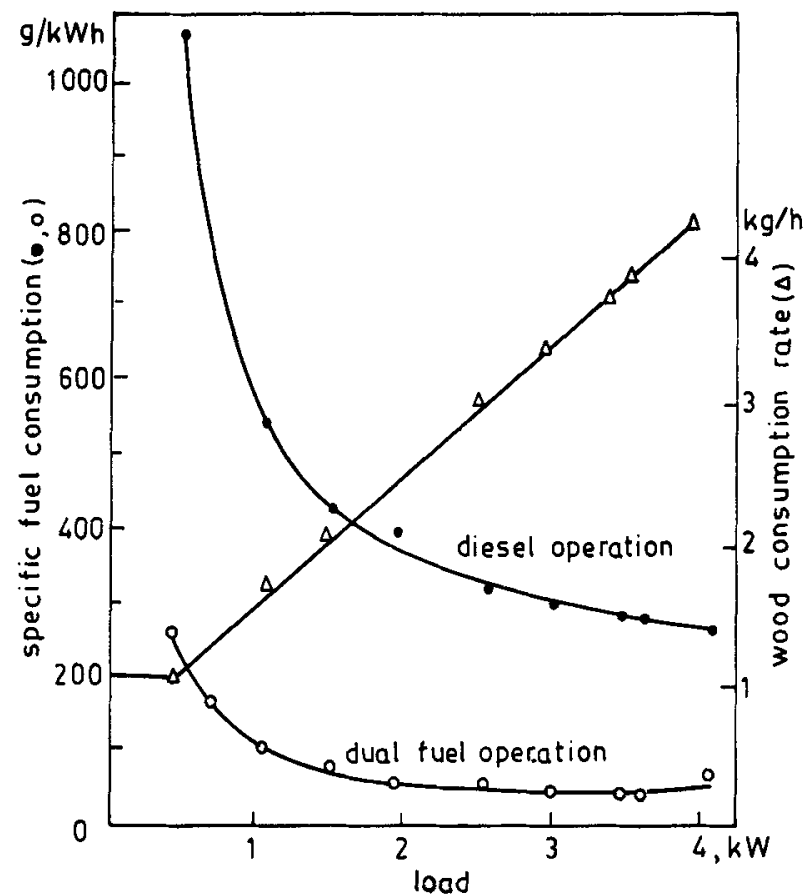

Figure 8. Performance of a $3 \cdot 7 \mathrm{~kW}$ engine generator set on diesel (Haridasan et al 1989).

the engine. The gas flow increases at the expense of the air and the energy available from the charge is adequate to meet the load even as the governor reduces the diesel further.

In the simple designs provided in the field, the diesel flow is measured by clocking the time of flow of specified quantities of diesel manually. Since this operation takes time, it takes about five to six minutes to ascertain that the engine is tuned to a high diesel replacement.

The specific fuel consumption (SFC) of the engine-generator set in the diesel mode and the dual fuel mode are shown in figure 8 along with the wood consumption. The lowest SFC in the diesel mode is $280 \mathrm{~g} / \mathrm{kWh}$. Figure 9 shows the gas consumption and the diesel replacement with load. As can be noticed the diesel replacement goes to as high as $93 \%$ at $70 \%$ full load and $85 \%$ at full load.

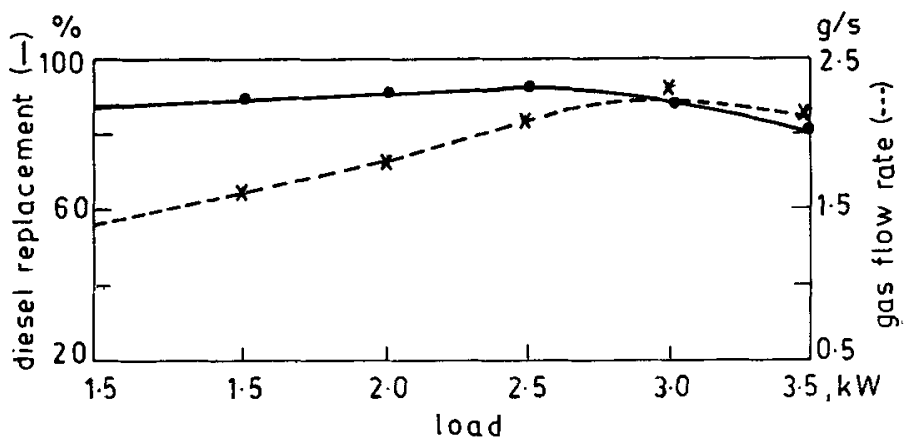

Figure 9. Performance of the engine generator set on dual fuel (Parikh et al 1988). 
In all the tests conducted, there have been no problems of operation with varying loads except when the load was thrown off and when tuning diesel flow at part loads. During load throw-off, the engine races and, on occasions the gas ingested in the transition stage burns up in the exhaust with a loud noise. If at the transition stage, the air valve is opened quickly enough, the operation of the engine continues normally.

\subsection{Gas carburettor}

In electrical applications, frequent load changes and load throw-off could commonly occur. In such situations the engine operation on dual flow is likely to become unsteady, particularly when the load is thrown off. The unsteady operation is due to the following two reasons: (a) The charge becoming fuel-rich resulting in the exhaust catching fire when the load is suddenly applied, and (b) the diesel injection being completely cut off when a sudden load throw-off occurs depriving an ignition source to the gas charge. In order to take care of such situations a carburettor is used on the gas-air mixture. It has a butterfly valve actuated by a feedback from the diesel governor, controlling the gas-air mixture inducted into the engine. An additional air valve helps in starting on diesel by providing the minimum air required to run the engine on no load condition, figure 10 shows the details of the carburettor. The diesel

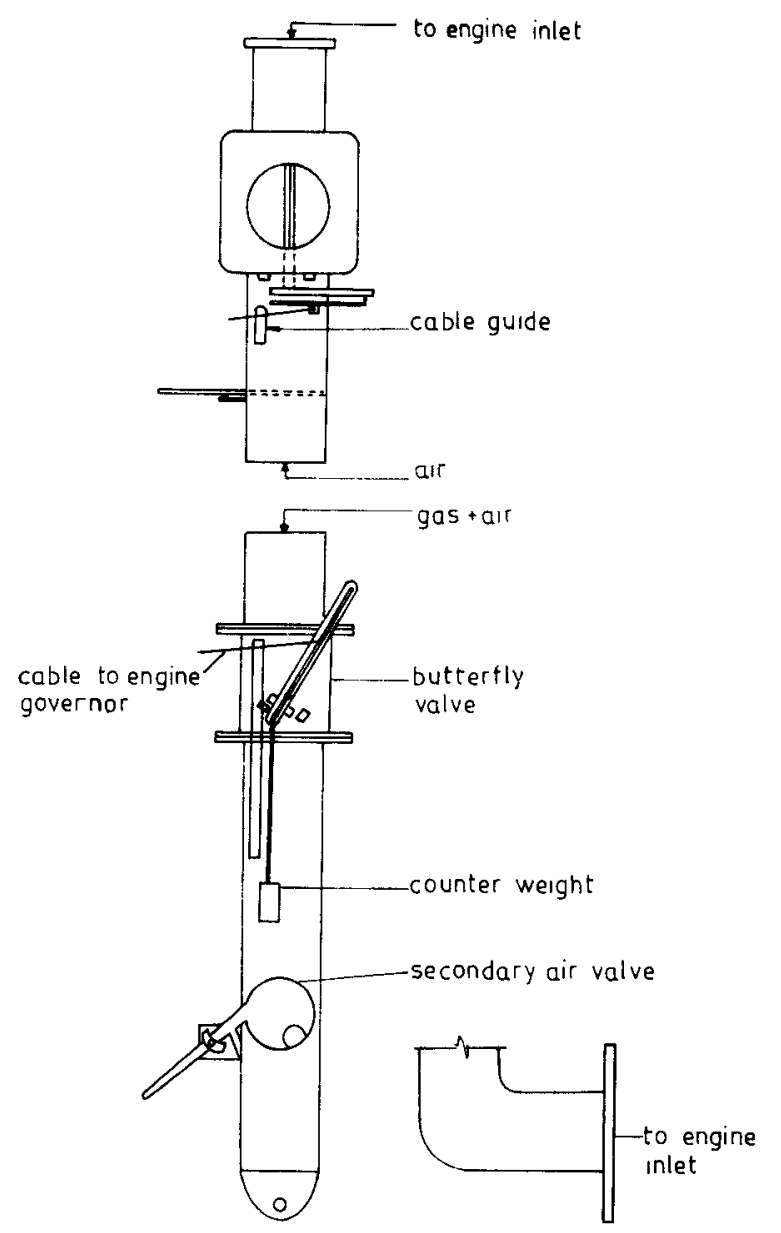

Figure 10. Details of the carburettor. 
injector is locked in a position in which the engine responds to load changes with an average diesel replacement of about $80 \%$ at varying load conditions. The device eliminates the need for tuning of the charge to the engine in the field by the operator. Experience in the laboratory and limited field trials at a field station at Hosahalli with this device have been satisfactory. This unit helps in maintaining a steady engine RPM and hence a steady generator voltage, resulting in a regulated supply to the voltage stabiliser for further use downstream.

\subsection{Field experience}

In the earlier discussion, some aspects of the field experience have been brought out. These will now be summarised systematically.

Amongst the field problems, the most important ones relate to the air-nozzle region and the bottom cap. Even when the gasifier was used as per the specifications in the manual provided by the designers, the air nozzle would crack up and burn out near the welded joint at the inner wall after $300 \mathrm{~h}$ of operation in a few places and, after $900 \mathrm{~h}$ in others.

The earlier experience as reported in SERI (1979) is as follows: "Mixtures of steel alloyed with nickel and chrome were used for the hearths of wood gas generators. Before rationing, the hearths contained about $20 \%$ chrome and $20 \%$ nickel; after rationing $18 \%$ to $25 \%$ chrome and $2 \%$ to $4 \%$ nickel. The combustion zone operates at 1200 to $1300^{\circ} \mathrm{C}$ and the hearth material up to $1000^{\circ} \mathrm{C}$. Therefore, the life of the hearth was usually only 5,000 to $20,000 \mathrm{~km}$ (100 to 400 hours at an average speed of $50 \mathrm{~km} / \mathrm{h}$ !) depending on the driving conditions, even with first-rate material."

However the above situation is unacceptable from an economic point of view today. The issue regarding the bottom cap has already been brought out. The likely malfunctioning of the bottom cap was anticipated by us and therefore, critical warnings regarding the problems associated with inadvertent leakages were provided in the manual. Also, the procedure of checking in the field for leakages by a simple method using a burning wick before igniting the gasifier was made mandatory. Despite all these, there were about three cases where the failures of the systems were traced to the above cause. Therefore with some rethinking on the design concept and based on some earlier experience, a design involving the water seal was implemented, instead of the use of the bottom cap.

The material preparation, namely producing wood chips of relatively small size, was an issue which was pointed out $b_{f}$ the users as being cumbersome. Also the electrically operated cutting device supplied with the system did not seem to meet the requirements. Modification of the cutting device was therefore called for. The questions about the size of the wood chips had also to be re-examined.

The gasifier system was fabricated from stainless steel and mild steel coated with corrosion-resistant paint. The reactor shell and the cyclone were of stainless steel. The water trough, filter container and the damper were of mild steel. Experience in the field showed that the mild steel components would not last long and there was extensive corrosion of many parts. Therefore, there was a need to use stainless steel instead of mild steel for these parts. The other alternative was to increase the thickness of the mild steel parts, something which was not desirable as the total system weight would increase and corrosion would not be prevented. A careful review was also made of the various elements of the system keeping in view that most applications are for water pumping. 
There was concern expressed by many users about the moisture in the wood chips. It was said that it would not be possible to procure large amounts of wood chips and dry and store them for use during the rainy season. As such an auxillary system for drying wood chips was needed.

In spite of the many drawbacks and limitations cited above, about 160 systems which have gone to the field have performed reasonably well. Two surveys of Rao (1989) and Energy Consultants (1989) discuss the experience of many users. According to the latter, in which 67 systems were investigated for their performance in one year, they had together clocked about $17,500 \mathrm{~h}$ in the dual fuel mode, an average of $290 \mathrm{~h}$ per annum. About four systems were used for more than a thousand hours each. Only two systems broke down completely in one year. An estimate of the total number of hours of operation of all the 160 systems on dual fuel mode exceeds 30,000 hours.

Thus the field experience threw up several issues which were to be taken into account in the redesign of the gasifier system. In the following sections, all the above mentioned issues are discussed along with the work taken up on design modification, testing and implementation.

\subsection{The reactor}

As mentioned earlier, there were failures of the air nozzle in some field units. On close examination it was found that the use of seamless pipe AISI 310 material instead of a welded pipe was essential. This is because any manufacturing defect at the welded joint would result in leakages and short-circuiting of the gas and air to form a combustible mixture. That would result in the burn-out of the material. It is also true that the quality of the material used for welding was generally unknown. Thus a seamless pipe would eliminate such undesirable problems. A careful study of the welded joints threw some light on how to redesign the air-nozzle welding. Figure 11 shows a schematic of the details near the air nozzle. It is clear from the figure that the nozzle is held tight between two freely expanding thin cylindrical shells. These shells have the freedom to expand longitudinally and diametrically at elevated temperatures. Similarly the shells are free to contract when the system is cooling after shut-off. This is exactly what is happening in a gasifier operation. The air nozzle which is welded to both these shells constrains such movement.

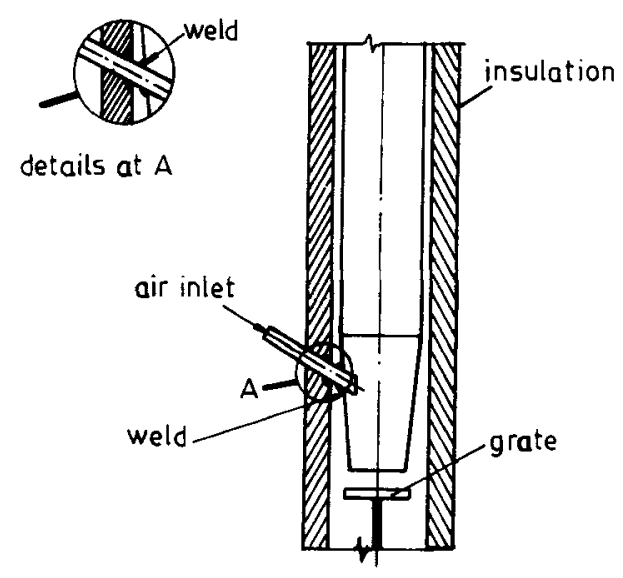

Figure 11. Welding details of the air nozzle. 


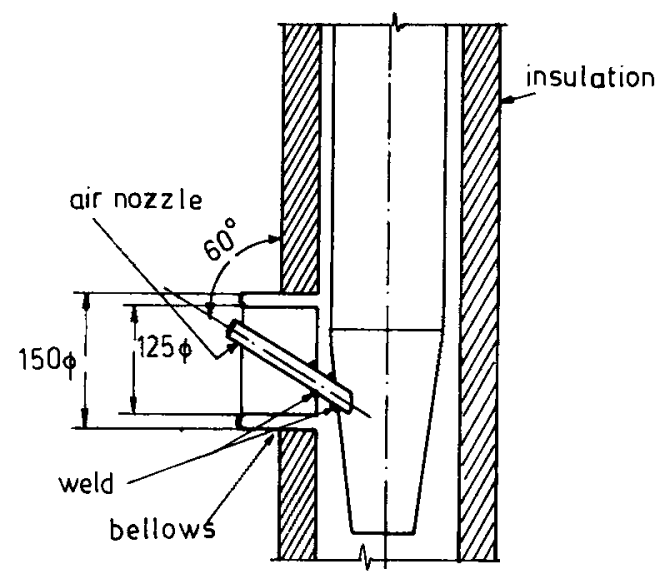

Figure 12. Details of the nozzle bellows (dimensions in $\mathrm{mm}$ ).

The thermal cycles that the shells and the nozzle are undergoing during gasifier operation result in stresses, causing tear in the material. Hence re-engineering of the air-nozzle welding to allow for thermal expansion of the nozzle was found necessary. A unit with bellows was designed as shown in figure 12. The design allows the nozzle to expand at elevated temperatures and contract when the gasifier is shut off. Here the nozzle is welded to the bellows fixed to the outer shell. Thus there is no direct link between outer and inner shells at the air nozzle. With these modifications it is hoped that air-nozzle failure will be eliminated. A few systems in the field already have the above modifications incorporated in them. However experience over a longer running period is necessary to establish the validity of the concept.

As described earlier, the bottom cap needed attention requiring redesign for acting as a positive seal. It was decided to use a water-seal. The direct use of such a seal in a hot environment would result in evaporation of water due to radiation and possibly due to conduction by direct contact. Therefore a radiation shield was designed to eliminate the above problem. The radiation shield as shown in figure 13 consists of two inverted cones so oriented as to reduce the radiation from the grate reaching the water. It is estimated that the radiation flux is decreased by a factor of twenty to twenty-five as compared to the situation without the two shields. It also turns out that ash flows and falls down into the water in the trough with ease. The grate is an integral part of the radiation shield. Thus with the introduction of the water-seal at the bottom, the gasifier can now be operated continuously without requiring any stoppage for ash removal.

\subsection{Cooler, water trough and damper}

The cooler which was designed for a nominal flow rate of $3 \mathrm{~g} / \mathrm{s}$ required by the $3.7 \mathrm{~kW}$ diesel engine proved effective except for frequent maintenance involved in cleaning the inner surface of the cooler. The cleaning was required to maintain the heat transfer, as fouling of the inner surface of the cooler causes reduction of its performance. Increasing the gas generation rate to energise higher capacity engines also resulted in the demand for a more effective cooling system.

As water is available at the site in all pumping applications, it was proposed to use water as the cooling medium, so that it could handle varying cooling loads. The 


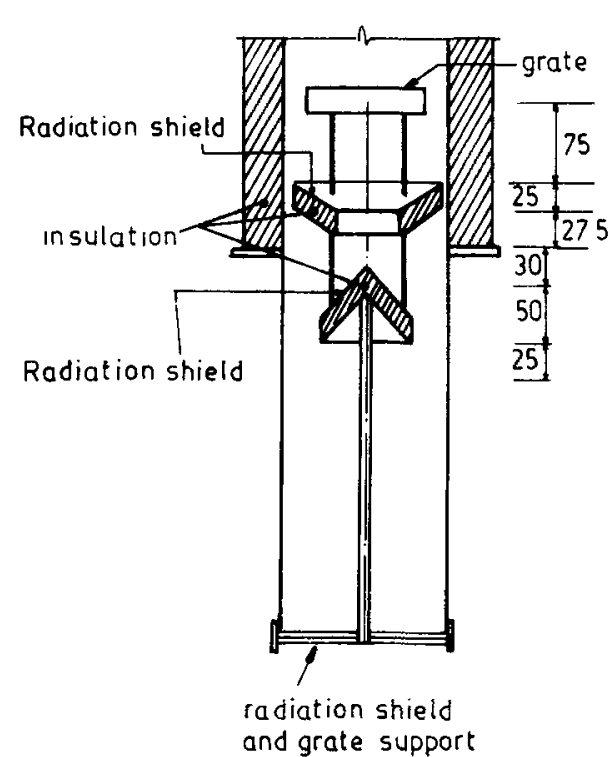

Figure 13. Details of the radiation shield and the grate holder (dimensions in $\mathrm{mm}$ ).

added advantage of using water for cooling is its ability to clean the gas. The temperature of the gas at the gasifier outlet is about $620 \mathrm{~K}$. This means that heat has to be removed at the rate of about $1 \mathrm{~kW}$ to cool the gas. With a temperature rise of $5 \mathrm{~K}$ between the inlet and the outlet, $50 \mathrm{~g} / \mathrm{s}$ of water flow rate is required. This is about $180 \mathrm{~kg} / \mathrm{h}$ or $0.6 \%$ of the nominal pumping capacity of the $3.7 \mathrm{~kW}$ diesel engine pumpset and would therefore be satisfactory.

Using water continuously for cooling called for change of material of the cooler and the water-trough. This was essential as the mild steel components were found corroded in the field. Therefore the case for using stainless steel for most of the gasifier system components became strong. The cooler, the cyclone and the damper were modified suitably and are being now fabricated from AISI 430 stainless steel.

A stainless steel tube of $0.1 \mathrm{~m}$ dia and $2 \mathrm{~m}$ length with a swirler was used as the cooling device. Along with cooling the gas, the spray also cleaned it. Experiments were conducted to quantify it. With the use of water in the cooling train the dust level in the gas reduced from $130 \mathrm{ppm}$ to a level of $50-60 \mathrm{ppm}$.

The gasifier and its cooling train are always under engine suction which ensures that any leakage in the system will only cause the outside air to leak into the system. Therefore the chances of the wood gas leaking out to the ambient are minimised. Hence the pollutants from the gasifier are limited to what is present in the cooling water. Though no tar can be seen in the effluent cooling-water, it carries the characteristic smell, and tar in traces cannot be ruled out. However, as of now, we have not been able to quantify it.

\subsection{The cutter}

The wood cutter (a high speed, portable circular saw) used for preparing woodchips was of a commercial variety and was found unsuitable for field application because of its design limitations. The cutter was specifically designed to be used intermittently for cutting plywood and could not handle the cylindrical stock of wood without 
getting overloaded. Therefore a cutter which can handle continuously heavy duty operation was necessary.

A circular saw driven by a $0.75-\mathrm{kW}$ continuous duty moti $:$ is now mounted on a framework. The top of the frame is covered for safety. Provision is made to vary the length of the wood chips. With this design a larger diameter $(100 \mathrm{~mm}) \log$ can be cut easily. This modification has resulted in lowering of the cost and in reliable operation and better performance.

\subsection{Drier for wood chips}

The percentage of moisture in the wood varies between 10 and $40 \%$ in the field. For reliable gasifier operation it is necessary to restrict the moisture content to within $20 \%$. Hence one needs a drying procedure to reduce the moisture content of the wood chips. Sun-drying being inexpensive would be best provided there is enough open space and sunshine. In places where it rains for considerable periods every year, as for example the Dakshina Kannada district or Port Blair, such procedures are ineffective. The use of the hot exhaust of the engine was considered an obvious and a good possibility for drying operations. A 15-kg capacity drier has been developed to use the exhaust from the $3.7 \mathrm{~kW}$ diesel engine as shown in figure 14 . The drier consists of an annular space and a conical hopper where wood is loaded for drying. Hot gases from the engine are allowed to expand in the annular space. The outside of the drier is insulated using mineral wool. The hot gases are then allowed to pass through the bed of wood chips. The temperature at the inlet to the drier is of the order of 625-675 K. Ports are provided at the top and bottom for easy loading and unloading of wood chips. The drier is capable of reducing the moisture content in the entire charge of $15 \mathrm{~kg}$ of wood chips from $40 \%$ to about $10 \%$ in $130-150 \mathrm{~min}$ of operation. The dried wood chips should suffice for 3 to $5 \mathrm{~h}$ of operation depending on the load. The temperature of the exhaust gas from the drier is at about $330 \mathrm{~K}$. If the wood is less wet before drying, the duration of operation is reduced. One such unit is in the field at Hosahalli in Karnataka for evaluation.

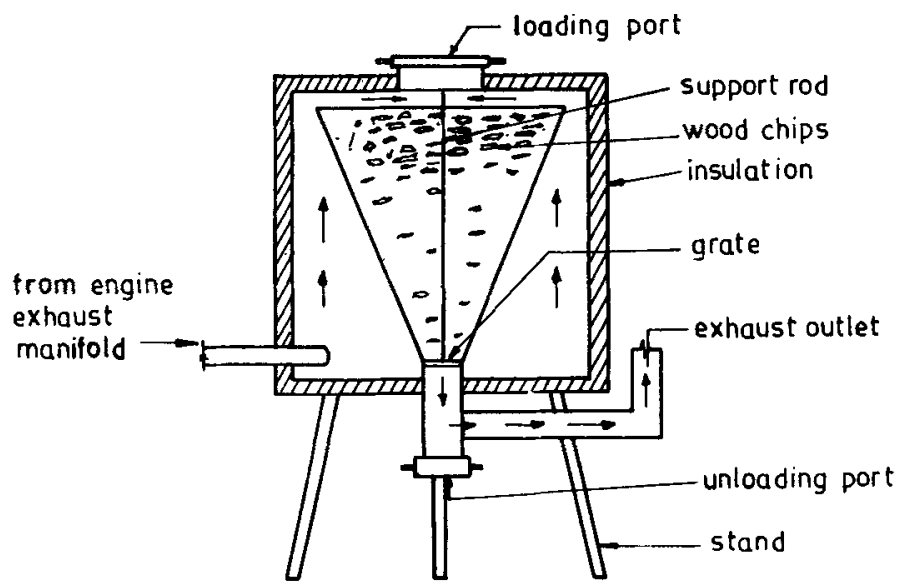

Figure 14. Drier details. 


\subsection{Size of wood chips}

While measuring the temperature inside the reactor it was noticed that a steep temperature gradient exists between the air nozzle and a point $500 \mathrm{~mm}$ above it. It was argued that part of the air flowing from the top and the nozzle would have caused the movement of the pyrolysis zone to above the nozzle. The measurements indicate a pyrolysis front moving up above the air nozzle at a rate of about $0 \cdot 15-0 \cdot 175 \mathrm{~mm} / \mathrm{s}$. It must be remembered that this is the relative movement of the pyrolysis front against the nominal downward movement of wood chips at the rate of $0.25 \mathrm{~mm} / \mathrm{s}$. Figure 15 shows the core temperature history of a $25 \mathrm{~mm}$ diameter wood sphere inside the gasifier. The movement of the pyrolysis front is a favourable situation for a wood gasifier operation, because no uncharred wood would then enter the combustion zone and thus generate poor quaiity gas. With $35 \pm 5 \%$ of the air coming from the top, it is noticed that some combustion of pyrolysis gases is initiated in the zone much above the air nozzle. This has been called the flaming pyrolysis by Reed et al (1984). This way the reactor would receive only char at the air nozzle zone.

Experiments indicate the cracking of wood pieces of diameter larger than $25 \mathrm{~mm}$ during pyrolysis. Similar observations have been made by others (Roberts 1970; Murthy 1972; Mukunda et al 1984). This property of the wood is utilised to increase the size of wood chips to be loaded into the reactor. Experiments were conducted to study the size reduction of the wood piece inside the reactor. They clearly indicated that in the zone $300 \mathrm{~mm}$ abovis the air nozzle the char pieces would start cracking radially and more predominantly along the growth rings. This would mean that the combustion zone would still receive only fragments of the large wood chips.

It was found that cylindrical wood pieces of $40 \mathrm{~mm}$ dia and $40 \mathrm{~mm}$ length were satisfactory as compared to the $15 \times 15 \times 40 \mathrm{~mm}^{3}$ size chips recommended earlier. Several runs have shown satisfactory performance. More experiments are planned before recommending large size chips for field use.

With the increase in the size of the wood chips, the chip generation rate will be five-fold greater. This would mean less effort for the user.
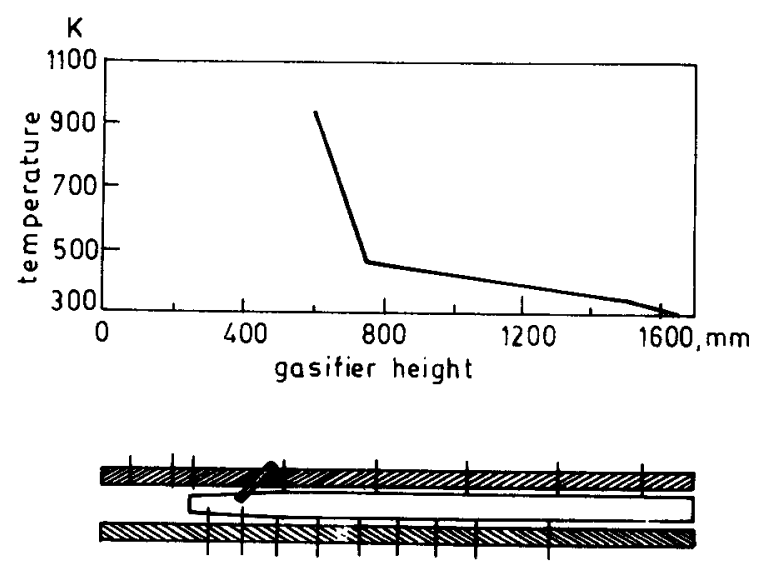

Figure 15. Variation of core temperature of a $25 \mathrm{~mm}$ dia wood sphere with time as it travels down from the gasifier top. 


\subsection{The cleaning system}

In the earlier field units, the cleaning system included a gas water contact at the bottom water-trough and a positive filtering system, consisting of a coir mat sandwiched between layers of nylon fabric. The system proved efficient in cleaning the gas to a level of about $130 \mathrm{ppm}$ of tar and particulates. Even here there was an element of concern about the maintenance and replacement of the filter material.

Gases generated from the gasifier normally carry moisture upwards of $1000 \mathrm{ppm}$, apart from the saturation level at its temperature. This moisture has the tendency to condense in the pipeline, and collect submicron particles from the gas. Thus it leads to clogging of the pipes.

Therefore a cold cyclone is introduced into the circuit to remove any moisture and dust in the gas. A packed bed sand filter has been designed to clean the gas. As the basic design data of packed bed filters were not available in the literature, it was necessary to carry out experiments on different particle ranges to obtain the pressure drop characteristics.

Coir pith, which has the tendency to hold 3-4 times its own weight of moisture, has been used to eliminate the moisture in the gas. A packed bed of about $100 \mathrm{~mm}$ thickness is used for the purpose. Studies similar to that of the sand-bed have been made to obtain the pressure drop across the bed. Experimental results on the wet bed indicated that there is a two-fold increase in the pressure drop as compared to the dry bed. The maintenance schedule for both the beds is of the order of 200 to 250 hours of operation. The beds are reusable after cleaning and drying.

Experiments with the above system have resulted in dry and clean gas. The combined tar and particulate level is less than $30 \mathrm{ppm}$ as recommended in SERI (1979). As both the beds are in cartridge form, the damper design has been modified to accommodate the cartridges inside it.

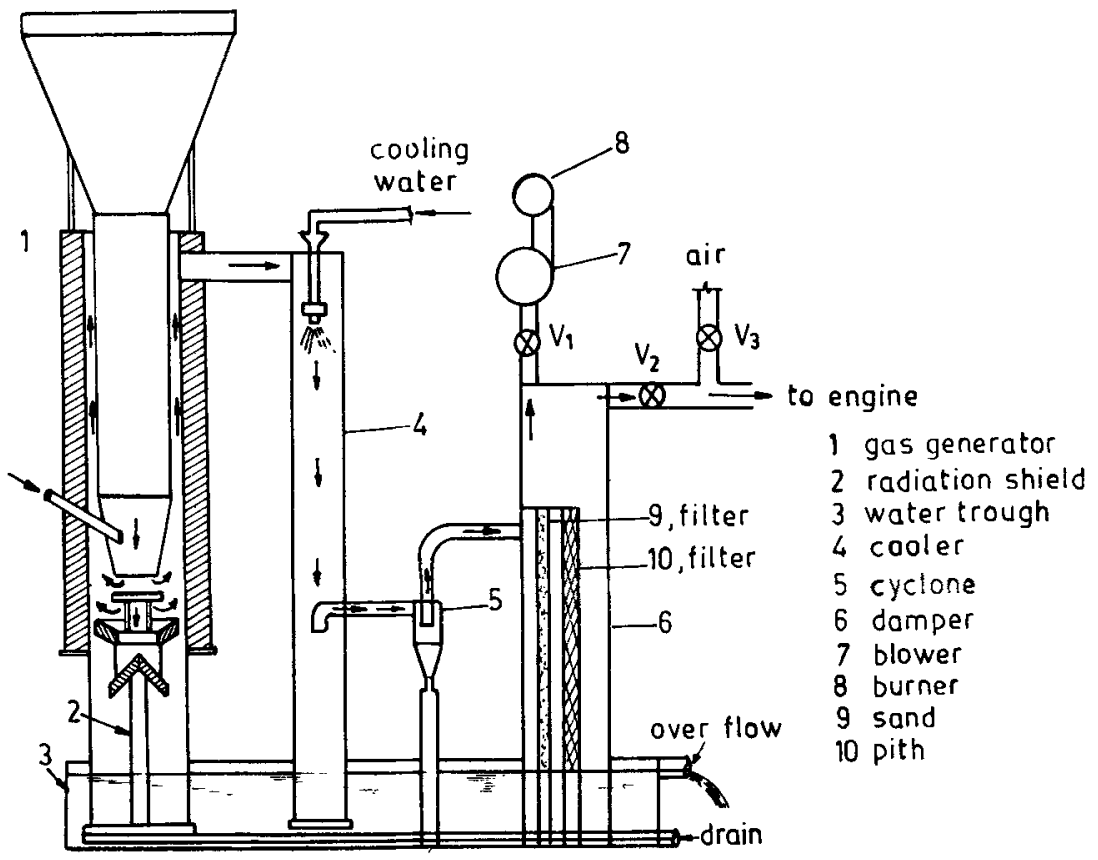

Figure 16. Gasifier, cooler and cleaning system, after modification. 


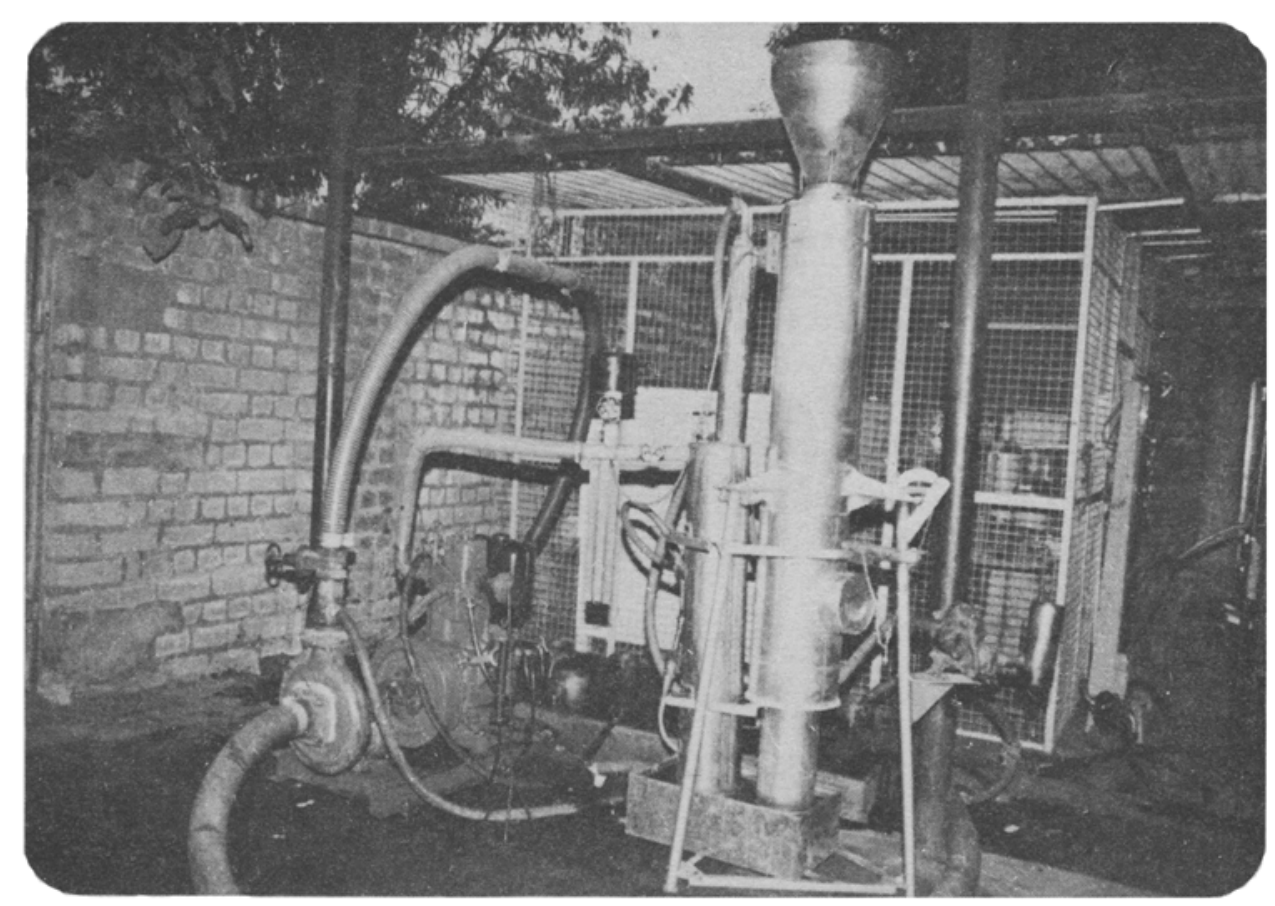

Figure 17. A view of the gasifier system.

With the above modifications and improvements, the complete system has resulted in a compact package with a single water-seal for all the elements. Re-engineering has been carried out to limit the requirement for too many tools for assembly and disassembly of the system. In fact one pair of spanners and a wrench are necessary and sufficient for the entire job. Figure 16 shows the schematic of the modified gasifier system and figure 17 is a view of the system.

\section{Cost of the overall system}

Cost is one of the important issues to be addressed for the system under consideration. Even with the escalation in the price of stainless steel by $100 \%$, the total cost of the basic system has remained the same. This has been achieved by a review of the functional requirements of the various elements of the gasifier system in the field. Due to the non-availability of aluminium tubes for the radiant cooler, an alternative was very essential. Therefore a stainless steel cooler with water spray was designed as a substitute. Since water is used as the cooling medium, the question of large surface area does not arise. Thus the diameter of the cooler tube was reduced by $33 \%$. This in fact reduced the cost of the cooler unit significantly.

The overall height of the system has been reduced by $0.5 \mathrm{~m}$. Hence the ladder for loading the wood chips has been eliminated. Instead a small platform has been provided and is found to be adequate.

The filter unit was modified to serve two functions, (a) as a damper, and (b) as a filter cartridge holder. Thus one more element namely the filter holder was eliminated from the system. 
From figure 16 it is seen that all the elements of the gasifier system are designed to have water-seals at the bottom. This has the advantage of easy accessibility for cleaning and a common water-trough. Thus a single small water-trough made of stainless steel has replaced the earlier large mild-steel water-trough. Complexity in fabrication is also eliminated.

The compactness of the overall system has resulted in the design of a stand with provision to tilt the gasifier unit for maintenance. This enables the user to carry out the maintenance single-handed.

The complete system as shown in figure 16 but without the wood cutter and the drier weighs about $104 \mathrm{~kg}$. It is currently priced at around $\mathrm{Rs} .10,000$ by a manufacturer in Bangalore who fabricates these units in small numbers of about a hundred a year. The complete package with the engine pumpset and the cutter, including a 2-year warranty but without the drier, is currently priced at Rs. 30,000 .

Table 6. Summary of the comparative features of the present wood gasifier and of older designs.

\begin{tabular}{|c|c|c|}
\hline Features & Older designs & Present design \\
\hline Power rating & For use with $15-150 \mathrm{~kW}$ engine & For use with 3.7 to $7.5 \mathrm{~kW}$ engines \\
\hline Fuel & $\begin{array}{l}\text { Sized }\left(2.5 \times 2.5 \times 5 \mathrm{~cm}^{3}\right) \text { wood cubes } \\
\text { with moisture contents less than } \\
10-15 \%\end{array}$ & $\begin{array}{l}\text { Sized }\left(1.5 \times 1.5 \times 4 \mathrm{~cm}^{3}\right) \text { wood or other } \\
\text { biomass cubes with moisture contents } \\
\text { upto } 20 \%\end{array}$ \\
\hline \multirow[t]{8}{*}{ Reactor } & - Closed top & Open top \\
\hline & $\begin{array}{l}\text { - Air entry through multiple air } \\
\text { nozzles at the combustion zone }\end{array}$ & $\begin{array}{l}\text { Air entry from the top and from a single } \\
\text { air nozzle at the combustion zone }\end{array}$ \\
\hline & - Bottom closed & Bottom water-sealed \\
\hline & - Low $L / D$ & High $L / D$ \\
\hline & $\begin{array}{l}\text { - Flow of solids with external } \\
\text { assistance }\end{array}$ & Flow of solids without external assistance \\
\hline & $\begin{array}{l}\text { - Localized pyrolysis, combustion and } \\
\text { reduction zones }\end{array}$ & $\begin{array}{l}\text { Stratified pyrolysis, combustion and } \\
\text { reduction zones }\end{array}$ \\
\hline & - Operation in batch mode & Operation in continuous mode \\
\hline & - About 100 to $200 \mathrm{~h}$ of hearth life & Above $1000 \mathrm{~h}$ of reactor life \\
\hline \multirow[t]{2}{*}{$\begin{array}{l}\text { Cooling cleaning } \\
\text { system }\end{array}$} & $\begin{array}{l}\text { - Cleanliness of the gas }-200 \mathrm{ppm} \text { of } \\
\text { tar and particulates }\end{array}$ & Cleanliness of the gas - below $30 \mathrm{ppm}$ \\
\hline & - Drier rarely used & Has a reusable drier \\
\hline \multirow[t]{4}{*}{ System } & - Mostly disposable filters are used & Has a reusable filter \\
\hline & - System weights variable & System weight: about $100 \mathrm{~kg}$ \\
\hline & $\begin{array}{l}\text { - Difficult to dismantle without special } \\
\text { tools by one person }\end{array}$ & $\begin{array}{l}\text { Can be dismantled by one person using a } \\
\text { single spanner and wrench }\end{array}$ \\
\hline & - Mostly carbon steel construction & Mostly stainless steel construction \\
\hline Performance & - Gas calorific value -4 to $5 \mathrm{MJ} / \mathrm{kg}$ & Gas calorific value -5 to $6 \mathrm{MJ} / \mathrm{kg}$ \\
\hline
\end{tabular}




\section{Concluding remarks}

This paper has considered the design evolution of a small wood gasifier-engine system. The essential principles of design and the novelty of the design in relation to earlier classical designs (see table 6 for a quick summary) are brought out in terms of the dual air entry from the air nozzle and from the open top, and the reactor design with annular passage. The performance characteristics of the system have been discussed. The principal and unique feature of the present design is the very high diesel replacement - up to $85 \%$ - achieved consistently and over long durations at full load. The deployment of the system in about a hundred and fifty locations and operation by field personnel have brought out the drawbacks existing in the earlier prototypes and have resulted in various improvements.

The improvements in design and attempts to meet user requirements have resulted in a cost effective compact system. Elimination of the requirement of consumables like asbestos rope and filter material has reduced the operating and maintenance cost, thus making the system more reliable and, hopefully, more user-friendly.

Some of the elements and concepts like the bottom water-seal, radiation shield, packed-bed filter, gas drier and wood chip drier, as proven in the $5 \mathrm{~kW}$ gasifier system, have resulted in their adoption in the $100 \mathrm{~kW}$ system also.

The authors thank the reviewers for their many useful comments and suggestions. The results presented here are the outcome of the projects on "Wood Gasifiers" administered and financed partly by the Karnataka State Council for Science and Technology, Bangalore, and by the Department of Non-Conventional Energy Sources, New Delhi. The authors are grateful to them for the support provided.

\section{References}

Bhama A G, Kapre D V, Ravi Kumar B V, Sanjeev Nair, Chunniwala S A, Katkar R M, Parikh P P 1988 Test report of qualifying testing and performance of MMFE gasifier system, Report, Indian Institute of Technology, Bombay

Dasappa S, Vikram Reddy, Mukunda H S, Shrinivasa U 1985 Ambio 14: 275-279

Energy Consultants 1989 Diagnostic study of gasifier and Stirling engine systems installed in 1988, Report prepared for the Department of Non-Conventional Energy Sources, Bhopal

Finkbeiner H 1937 Hochleistungs Gaserzeuger für Fahrzeugbelrieb und ortfeste kleinanlagen, Berlin

Haridasan T M, Muthu Subramanian P, Sooriamoorthy C E, Paliwala K 1989 Consolidated programme report, Madurai Kamaraj University, Madurai

Kaupp A, Goss J R 1984 Small-scale gas producer engine system, GATE publication, GTZ, Gmbh, Germany

Lutz H, Kuhl E 1942 Examinations of gas-cleaning devices, Berlin

Mukunda H S, Paul P J, Shrinivasa U, Rajan N K S 1994 Proc. 20th Symposium on Combustion (Philadelphia: Combustion Institute)

Murthy K A 1972 Combust. Sci. Technol. 5: 135-146

Parikh P P, Bhave A G, Kapre D V, Shashikantha 1988 Study of thermal and emission performance of small gasifier dual fuel engine system $J$. Biomass (preprint)

Rao P 1989 Techno-economic analysis of biomass gasifier - A case study of the implementation programme in Karnataka, Presented at 1st National meet on Recent Advances in Biomass Gasification, Indian Institute of Technology, Bombay

RAPA 1986 Research on the Gasification of Rice husk in Indonesia, Rural energy, RAPA Bulletin, FAO, Bangkok 1986/1, pp. 14-16 
RAPA 1988a Development of Small (3-5kW) Gasifiers in India, Rural energy, RAPA Bulletin, FAO, Bangkok $1988 / 1$, pp. 23-27

RAPA 1988b Rice husk gasification network in Asia and the Pacific region, Rural energy, RAPA Bulletin, FAO, Bangkok 1988/1, pp. 35-42

Reed T B 1981 Types of gasifiers and gasifier design considerations, Biomass gasification: Principles and Technology, Noyes Data Corp., New Jersey

Reed T B, Levic B, Das A 1984 Biomass Gasification for Power, Fuels and Chemicals, Sth Canadian Bio-energy R \& D seminar, Ottawa, Canada pp. 48-55

Roberts A F 1970 Combust. Flame 14: 261-270

SERI 1979 Generator Gas The Swedish Experience from 1938-1945, (translation), Solar Energy Research Institute, Colorado, NTIS/Sp. 33-140

Shrinivasa U, Mukunda H S 1984 Sādhanā 7: 137-154

Strauss W 1975 Industrial gas cleaning, International Series in Chemical Engineering (New York: Pergamon Press) vol. 8 pp. 248-314 